Orbis Tertius, vol. XXII, $n^{\circ}$ 26, e050, diciembre 2017. ISSN 1851-7811

Universidad Nacional de La Plata

Facultad de Humanidades y Ciencias de la Educación

Centro de Estudios de Teoría y Crítica Literaria

\title{
Cómo se investiga un crimen. Detectives y literatura detectivesca en Buenos Aires entre los siglos XIX y XX
}

\author{
Lila Caimari * \\ * Universidad de San Andrés, Argentina.
}

\section{PALABRAS CLAVE}

Literatura policial

Cultura policial

Policía, historia

Detectives, historia

KEYWORDS

Police literature

Police culture

Police, history

Detectives, history

\section{RESUMEN}

Apoyándose en un corpus de escritos informales de policías de la ciudad de Buenos Aires publicados entre fines del siglo XIX y principios del XX, el trabajo se ocupa de las narrativas de la pesquisa nacidas en el seno de la institución policial. Argumenta que en el contexto decimonónico de expansión de un imaginario literario de la detección, los policías debieron redoblar esfuerzos para construir una voz profesional sobre la investigación y el quehacer de los detectives estatales, y que esos esfuerzos resultaron en discursos no del todo autónomos de las reglas de la ficción. A lo largo de su desarrollo, el trabajo reflexiona, además, sobre la relación entre policía, literatura policial y culturas policiales.

\section{ABSTRACT}

Drawing from a body of informal writing authored by Buenos Aires policemen between the late 19th and the early 20th centuries, this article deals with informal chronicles of detective investigation. It argues that in the context of the expansion of a literary imagination about detection, in the late 19th century, it was hard for policemen to build up a professional voice about the work of public detectives. Ultimately, their discourse was never completely free from the influence of literary voices. Moreover, the article reflects on the complex relationship between the police force, detective literature and police cultures. 
Entre el gremio policial argentino, para no hacer mención de los extraños, las obras de Conan Doyle despertaron siempre vivo interés. 1

Este trabajo se interroga sobre la relación entre la narrativa policial literaria y la narrativa de la pesquisa nacida en las agencias estatales del orden, en un momento de reforma profesionalizadora de la práctica de la investigación policial de Buenos Aires. El origen de este interrogante se sitúa en un conjunto de investigaciones en el Centro de Estudios Históricos de la Policía Federal, donde tomé contacto con un vasto universo de textos "de afición" escritos por policías entre fines del siglo XIX y mediados del XX. Dicho corpus incluía crónicas en primera persona, incursiones en el tango, ficción, abundante poesía y colecciones de guiones radioteatrales, cinematográficos y televisivos, entre otros materiales. El análisis de esos textos pronto delineó un argumento general en relación al papel primordial de la experiencia en la práctica escrita de los policías: la experiencia, y la experiencia sola, provee un repertorio de temas — la calle, los márgenes, la noche, el sufrimiento, el crimensobre los que la policía siempre ha reclamado autoridad cognitiva superior (Caimari 2012; 2013).

Proveedora de materia prima, entonces, la experiencia policial funciona en el doble sentido de acumulación de saberes vivenciales y de intimidad con el peligro. La palabra "experiencia", recordemos, lleva inscripta en su etimología la noción de superación de un riesgo. Comparte una raíz con “experimento” y “experto”, pero también con "perilous” (peligroso) (Yi-Fu-Tuan 2008: 9). En esta concepción activa del término, tener experiencia implica haberse aventurado en lo que no es familiar, en lo incierto y potencialmente amenazante: en lo que es oscuramente desconocido a los profanos. La experiencia que reclama el policía que escribe sitúa esa forma de la puesta en riesgo (que puede tener sentido físico o emocional) en el centro de su campo de sentido. Sobre la exaltación de esta diferencia, el policía radicaliza su posición en relación a interlocutores y competidores que se aventuran en la narración de los mismos temas — criminólogos, juristas, escritores, periodistas (Monjardet 1994: 224). La simple colocación del policía de calle en relación al mundo real lo inviste de una insuperable ventaja cognitiva, lo convierte en autoridad última de un saber que es social, urbano y existencial. Así pues, la experiencia preside sobre la práctica de la escritura, marca lo que la hace única, es prueba de una forma de distinción rea que opera tanto hacia dentro como hacia fuera de la institución.

Partiendo de esta idea general, este trabajo se detiene en un núcleo de narrativas tempranas de la investigación policial del crimen. Sus autores constituyen un grupo mezclado — pesquisas, sumariantes, policías de calle- que en su relato del quehacer de la investigación entrelazaron saber policial con dosis diversas de escritura literaria y burocrática.

\section{Detectives y literatura detectivesca}

“¿Leen novelas policiales los policías?”. En los años que van de 1969 a 1989, el comisario Eugenio Zappietro volvió varias veces sobre el asunto. Volvió porque su respuesta era afirmativa: los policías leen policiales. Como tantos, leen por el placer de desentrañar misterios. Pero también leen por curiosidad profesional, porque su experiencia les permite comparar realidad y ficción: “(...) esto es, la tarea policial cotidiana y la novela que se hace en un escritorio, planificando las dosis de misterio, violencia y acción.” (Zappietro 1986) Si el diagnóstico era difícil de comprobar, desde su puesto de director de la revista oficial de la Policía Federal Argentina, Mundo Policial, Zappietro hizo lo posible por confirmar este vínculo, difundiendo reseñas y comentarios de las novedades literarias locales e internacionales. Esta ecléctica revista institucional fue, entre otras cosas, una empresa de instrucción básica sobre el género policial, con extensas semblanzas de Georges Simenon, Edgar Wallace, Wilkie Collins, Conan Doyle, Agatha Christie, William Irish, John MacDonald, John Le Carré, entre otros.

Aunque ningún órgano oficial había dedicado tanto espacio al tema, la cuestión del vínculo entre pesquisas ficticios y reales ya era conocida en los ámbitos ilustrados de la institución. En 1934, por ejemplo, la colección de libros "Biblioteca Policial” (antecesora de la Editorial Policial) se había inaugurado con el título Policías de 
novela y policías de laboratorio, del célebre criminalista francés Edmond Locard —él mismo autor de memorias y textos periodísticos (Locard 1934). Allí se trazaba un paralelo entre los personajes de la literatura de enigma y el trabajo de la detección real. Se ocupaba de Sherlock Holmes, por supuesto, pero también del Monsieur Lecoq de Émile Gaboriau y del Dupin de Edgar Allan Poe, personajes que a esas alturas eran viejos conocidos de los lectores porteños (Lafforgue y Rivera 1996: 13; Laplaza 1945: 48-49; Setton 2009: 282; 2015). Que esta obra de Locard, de amplia difusión internacional, encabezara la primera colección de libros editados por la policía porteña fue responsabilidad del director de la empresa, Enrique Fentanes, animador de otras iniciativas educativas y figura próxima a los círculos oficiales. Según se indicaba, la traducción del francés era obra del mismísimo Jefe de Policía de la Capital, coronel Luis J. García.

¿Por qué incluir a los héroes de la ficción policial en las publicaciones internas de la policía? Al instalar en el imaginario popular al detective de perfil intelectual y metodología elegante, argumentaba Locard, la literatura contribuía a restaurar el respeto perdido gracias a los retratos del agente rústico de las novelas de Balzac y Victor Hugo. Locard atribuía un poder considerable a la literatura en la difusión de imágenes de la policía: si las cosas habían mejorado y los representantes de las fuerzas del orden de su tiempo gozaban de una estima relativa, esto se debía sobre todo a cambios en el tratamiento de estas figuras en esas novelas que "despertaban en el corazón de todo hombre al policía que en él dormita.” (Locard 1934: 11). La literatura podía (debía) participar de la empresa de transición del policía rústico al policía civilizado. Y además de proyectar una imagen culta, podía inspirar práctica efectiva. Argumentos apolíneos y énfasis en las destrezas de la mente eran ejercicios aconsejables para los policías, entonces, y por este camino, la jerarquía institucional emuló muchas veces el argumento de Locard en relación al potencial civilizatorio del cuento y la novela policial.

Por cierto, la policía porteña abrevaba de un universo de ficción "criminal” desde mediados del siglo XIX, cuando la moda del folletín y las “causas célebres” se había instalado en la prensa escrita. La emblemática compilación de Albert Bataille, Causas criminales y mundanas del año 1880 fue traducido por la Policía de la Capital en 1895 “para instrucción de su personal”, según rezaba la portada (Laplaza 1945: 44; Galeano 2009: 112; Barry 2008). La ficción de Victor Hugo también ofrecía material aprovechable. El inspector Javert — personaje de Los Miserables inspirado en las memorias de policías parisinos - tuvo un lugar en el imaginario de la fuerza porteña desde fines del siglo XIX, y de la misma cantera provenían modelos románticos de transgresor.

Es sabido que la causa célebre europea (la francesa en especial) tuvo una circulación transnacional muy extendida. Género híbrido, se nutría de la reproducción (o la imitación) de los alegatos desplegados en esos teatros del drama criminal que eran los juicios orales de las grandes ciudades europeas, que nutrían la humana curiosidad por el misterio del delincuente. Pronto pasaron por el tamiz del caso célebre algunos episodios locales, como el crimen de Barranca Yaco o la ejecución de Camila O’Gorman (Laplaza 1945: 30). La flamante Revista de Policía introdujo casos de este tipo desde el comienzo:

[La Revista de Policía] no descuidará tampoco una sección de lectura amena que encierre un fondo de enseñanza en cuestiones de este género y ejerciten la imaginación del agente, hincándolo en los medios de pesquisa o de investigación con que se consigue sorprender muchos criminales. $\underline{2}$

“Lectura amena” significaba, en este caso, lectura que combinaba instrucción, testimonio y ficción. Las narraciones sensacionales servirían para allanar el difícil camino de la profesionalización de la tropa, por entonces prioritario en la agenda institucional.

En sus líneas generales, los criterios de selección que aplicaban las revistas policiales no eran muy diversos de los del periodismo masivo. El espacio concedido al envenenador Castruccio, por ejemplo, se justificaba porque "La prensa diaria ha alimentado durante varios días la natural curiosidad en estos casos”. El perfil de asesino nato y el gran retrato a lápiz que lo acompañaba echaba mano de la misma colección de elementos científico-novelescos de

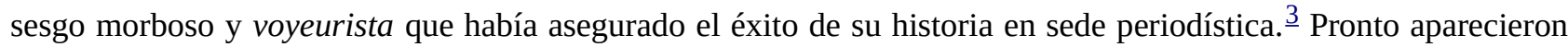
relatos de los casos más sonados de la jurisdicción, intercalando los ocurridos en París con secciones sobre 
criminales locales salidos de los reportes del mes - criminografías, en términos de Diego Galeano (Galeano 2009: 111). La Revista de Policía aprovechaba estas coberturas para dar lecciones de procedimiento:

Con motivo del crimen que ha conmovido últimamente la población de la capital, es conveniente hacer resaltar la necesidad de lo delicadas que son las primeras medidas que deben tomarse para evitar que los rastros dejados por los criminales sean borrados ó alterados, siendo ellos innumerosos casos los del procedimiento ulterior. 4

En versiones menos confrontativas de la autoridad pero no menos sensacionalistas que las de los diarios, los perfiles de criminales seguirían llenando páginas de las revistas policiales hasta muy entrado el siglo XX. Tensionada entre los mandatos profesionalizadores y los de la cultura masiva que también entretenía a los policías, esta encarnación de la prensa del crimen nunca perdió de vista su relación problemática con el género periodístico y literario. Así, los grandes casos incluidos en sus páginas convivían con editoriales críticos de la fascinación morbosa de los tiempos modernos, y con llamados al disciplinamiento de los policías cómplices del periodismo sensacional.

Como es evidente, todo esto plantea preguntas sobre la especificidad del punto de vista de los policías. Los redactores de las revistas institucionales no podían sustraerse a un contexto saturado de narraciones sobre su objeto de trabajo, allí donde diarios y revistas definían, cada día y en miles de ejemplares, los términos simbólicos del crimen. A pesar de las críticas al sensacionalismo, la policía participaba (y seguiría participando por muchos años) de una red de préstamos amplia y permisiva, donde las influencias iban en varias direcciones.

A fines del siglo XIX, la curiosidad por el delincuente fue desplazada por la fijación en el detective. Las razones del deslizamiento del drama criminal al héroe detectivesco no son claras - las interpretaciones extra-literarias aluden a cambios en el sistema legal inglés, que mejoraron la percepción pública de la justicia y la policía (Shpaier Makov 2011: 226). Al pasar del drama tribunalicio a los laberintos de la pesquisa, la ficción comenzó a depositar expectativas de emoción y entretenimiento en una actividad que atañía más directamente a la policía. El giro de la literatura tuvo ecos en las publicaciones de la profesión. En 1900, por ejemplo, la Revista de Policía de la Provincia de Buenos Aires publicaba como folletín, en varias entregas, la novela de Gaboriau, El crimen de Orcival, recomendando especialmente la lectura, porque "Trata de una de las notables pesquisas del célebre M. Lecoq, el agente de seguridad de más genio investigador que se ha conocido.”포

El ingreso de la ficción detectivesca a las bibliotecas policiales no resultó sencillo, sin embargo. El primer escollo remitía a las premisas mismas del género, pues en la literatura de enigma el cumplimiento de la ley y la captura del transgresor eran objetivos secundarios. Peor aun: esos elementos podían estar ausentes sin que dejara de cumplirse la misión última del género, que era la de develar una trama indicial hacia la verdad. Como se ha señalado a menudo, la devaluación del pesquisante estatal era uno de los supuestos fundantes de la literatura policial clásica, donde inspectores e investigadores institucionales funcionaban como figuras de la equivocación o del ridículo. En el mejor de los casos, eran tácitamente subestimados (Miller 1988: 3). Los policías no estaban para lucirse, sino para subrayar con sus torpezas el talento del detective privado —una operación evidente, por ejemplo, en el tratamiento que Conan Doyle reservaba a los interlocutores de su héroe Sherlock Holmes.

Observar la difusión del género detectivesco desde el punto de vista de los intereses de la policía permite volver sobre la noción del poder subversivo (o erosionante) de esta ficción. Pues esta idea, tan visitada en sede literaria, ha contribuido a ocultar otra, que resulta evidente al pensar el problema desde el punto de vista de los intereses de la institución policial: no obstante los desafíos a la autoridad que planteaba la ficción de detectives, la moda de la pesquisa operó como una aliada en sentidos que fueron decisivos en el largo plazo. En un contexto de trabajosa profesionalización de tropas policiales analfabetas, rústicas y mal equipadas, las historias de detectives pusieron en escena una de las raras dimensiones del quehacer policial donde primaban la razón y la ciencia. La descripción de la ficción de enigma como un dispositivo eminentemente crítico de la policía, en efecto, no debería pasar por alto que el auge de esta literatura coincidió con la construcción simbólica de la institución en muchas ciudades del 
mundo, y con el momento liminal de modernización de las policías urbanas. La policía moderna tiene, de hecho, una deuda fundamental con la ficción de la detección, una deuda que no se reduce a la elevación intelectual de la tropa, como quería la minoría de policías ilustrados. Es una deuda que toca a la construcción de una imagen de la institución en el público masivo, a la fijación de nociones de lo que hace la policía, de sus tareas y funciones en la sociedad. En este plano, el policial de enigma (como el procedimental, y como tanta ficción cinematográfica y televisiva contemporánea) cumplió una función ideológica principal, relegando a segundo plano los desencuentros y decepciones que la literatura deparó a los lectores policías. Al entronizar la aventura de la investigación, operó un recorte del quehacer policial que aisló y enfatizó capacidades técnicas, aptitudes intelectuales y sensibilidades perceptivas. El lugar paradigmático de la policía quedó definido en la escena del crimen, en los laboratorios o en los despachos donde se ponderaban hipótesis. Aun si resultaban fallidas-aun cuando ese policía se equivocaba, aun cuando era puesto en ridículo-estas intervenciones se mantuvieron ajenas al núcleo coercitivo que sostenía (sostiene) la inmensa mayoría de las intervenciones policiales del mundo real (Waddington: 1999).

Los enigmas literarios fundantes, y sus famosos detectives, colaboraron en una empresa simbólica difícil y muy cara a la institución policial. Fijaron la noción —objetivamente falsa, pero esencial a la construcción de una imagen de modernidad— de que la principal ocupación de la policía era la lucha contra el delito, la investigación sostenida del delito. Al hacerlo, distrajeron (distraen) de lo que la policía efectivamente hace. Es decir, de esa forma de patrullamiento genérico, indeterminado y a menudo brutal que constituye (siempre ha constituido) el universo cotidiano de la policía urbana.

\section{Pedagogías correctivas}

Los policías deberían leer policiales, decía la jefatura porteña. Pero muy pocos se animaban a escribirlos. Género exigente y codificado, el policial no se prestaba a las incursiones literarias "blandas": esos esfuerzos conducían por los caminos permisivos y sentimentales del melodrama, la viñeta picaresca o el poema elegíaco, muy visitados por la tropa policial (Sirimarco: 2010; Caimari 2012: 197).

La primera y principal vía de abordaje del policial literario tenía un sesgo correctivo-policíaco más que policial. Estaba marcada por la tensión entre literatura y verdad, por la validación de la autoridad cognitiva puesta en riesgo por la ficción. Era un ejercicio de cotejo incesante, donde la narración del pesquisa estatal procuraba competir con las voces forjadas por fuera de la experiencia del crimen. Es lo que hacía, por ejemplo, el comisario Laurentino Mejías en su libro de memorias, Policíacas(1927), donde procuraba corregir las fábulas del escritor Eduardo Gutiérrez apelando a la voz de la experiencia. Contra los mitos construidos por la literatura, la autoridad del policía invocaba su pergamino esencial, apelando a los detalles que sólo podían provenir del contacto personalcon el caso. $\underline{6}$

Para quienes transitaron el camino de la práctica de la detección a la escritura de la detección, este ejercicio de autoridad era difícil de resistir. En verdad, la operación ya era frecuente entre los detectives de ciudades europeas de mediados del siglo XIX: las narrativas de los "misterios de la ciudad", que tanta fortuna internacional lograron a partir de las variaciones locales sobre el modelo de los Mystères de Paris de Eugène Sue, pronto encontraron respuesta del oficial Vidocq, cuya obra Les Vraies Mystères de Paris incluía el programa correctivo en el mismo título (Kalifa 2013: 337). Los detectives de Scotland Yard, por su parte, se lanzaron a escribir para corregir la imagen de su quehacer producido por el éxito planetario de las novelas de Sherlock Holmes (Shpaier-Makov 2006: 122).

El impulso correctivo es tan perdurable en el tiempo y tan extendida en el espacio, que obliga a reflexionar sobre la singular posición del policía memorialista. Otros profesionales han incursionado en la crónica y la ficcionalización, por supuesto, pero ninguno ha debido hacerse cargo de las pautas establecidas en un género literario con códigos mundialmente aceptados y canales de difusión masivos. Desde fines del siglo XIX —el momento de despegue del proceso de profesionalización del cuerpo policial— el policía dispuesto a narrar su relación con el mundo del delito sabía que competía en desventaja con cuentos, novelas, periodismo (y más tarde, 
con el cine y la televisión). Sus narraciones existirían en el marco de una frondosa imaginación cuyas lógicas podían hacer la mímica del quehacer policial, pero le eran ajenas.

Corregir esta brecha era un propósito central, permanente (y fallido) de las primeras crónicas de la detección. Ya en 1912, el comisario Alberto Dellepiane dedicaba el prólogo de sus Memorias de un detective a deplorar la influencia de las novelas de Conan Doyle, responsables de lanzar la opinión "por un singular derrotero, que tiene mucho más de fantástico que de real” (Dellepiane 1912: 5). Dellepiane atacaba el endiosamiento del detective genial a partir de deducciones que consideraba habituales en cualquier cabeza pensante de la policía. Su libro estaba dedicado a mostrar que los detectives verdaderos, como él, no se limitaban a disolverse mansamente ante los rayos de inspiración de mentes superiores. Una agenda similar informaba la reflexión del prestigioso oficial carioca Elysio de Carvalho. En Sherlock Holmes en Brasil sostenía que la obra de Conan Doyle no era más que una "pálida copia de la realidad palpitante”, que el público lector debería conocer mejor (Galeano 2012: 71).

En un mundo donde la ficción de detectives parecía indetenible, los pesquisas más astutos no luchaban contra la literatura: se servían de ella para subrayar la distinción entre la seriedad del experto y la fantasía del artista. Luego de dirigir la más poderosa agencia de detectives de Estados Unidos, por ejemplo, Allan Pinkerton dedicó muchas páginas a demostrar que el ejercicio de la detección no se parecía en absoluto a las novelas de detección tan de moda en esa vuelta del siglo XX — estableciendo, de paso, que lo que hacía su agencia era cosa de profesionales y no de amateurs. La detección era un business sin nada misterioso, oscuro ni milagroso (Raczkowski 2003; Frisby 2007).

Como es sabido, credenciales similares sirvieron a Dashiell Hammett — que saltó a la fama luego de varios años como empleado de Pinkerton - para construir un lugar en el campo literario de entreguerras. Mientras se ganaba la vida reseñando libros, subrayaba con deleite las gaffes de sus colegas del género, que escribían como si sacaran sus ideas del métier de cursos por correo sobre Cómo ser detective. Incluso les dedicó un humillante catálogo de datos útiles: la diferencia entre un revólver y una pistola, la verosimilitud del uso del silenciador en escenas de homicidio, la secuencia del dolor que producían una herida de bala y una de arma blanca, etc. (Johnson 1985: 117120).

Entre los autores de policiales argentinos, no faltaron quienes respondieron a la crítica de los experimentados en la detección. No eran muchos, claro, pues la disociación entre ambas esferas era consideraba demasiado evidente para detenerse en la cuestión. Decía Borges: "El cuento policial nada tiene que ver con la investigación policial, con las minucias de la toxicología y la balística.” (1945: 74). Tardíamente, el escritor Adolfo Pérez Zelaschi entabló un diálogo con los policías porteños. Como disciplinado cultor del policial entendido como "una investigación racional de la violación de la norma”, Pérez Zelaschi procuraba diferenciarlo de la andanada de "falsos" policiales que circulaban en las industrias culturales, y que bajo ese rótulo narraban toda clase de aventuras. Era en la racionalidad de la investigación donde el escritor verdaderamente comprometido con el género establecía una alianza con el policial "verdad” de los policías: "El azar, el porque sí, lo casual, lo fortuito, lo no justificable, lo irracional, lo gratuito le son extraños, y este rasgo es el que diferencia al género de la novela, teatro o filme de aventuras, donde todas estas circunstancias tienen cabida normal. Y están proscritos de la policíaficción porque también lo están de la policía-verdad” (Pérez Zelaschi 1985: 85). De modo que una investigación racional (es decir, policial en ambos sentidos) debía conducir, en los dos casos, a resultados verosímiles, creíbles, perfectamente explicables, aunque ese desenlace resultara poco habitual, y aun sorprendente. En ese punto mínimo pero básico es donde se encontraban ambas narrativas. El escritor podía no instruir un sumario tal como verdaderamente se instruía un sumario, pero no podía llevar este desapego demasiado lejos sin poner en riesgo la credibilidad de su historia. Debía tomar algunos de estos elementos, pero no todos: "Si se atuviera a todos estaría haciendo historia policial que desde luego es otra cosa.”

El apego a la realidad que tanto importaba a algunos policías escritores no era en absoluto suficiente para el éxito, decía Pérez Zelaschi, volviendo decidido al corazón de la lógica literaria. La insistencia en los errores del escritor marcaba el límite literario de los policías, observaba, porque el ambiente debía ser verosímil al lector promedio 
(no al policía) “confirmándome en mi opinión de que la parte de realidad que la policía-ficción requiere es poca” (Pérez Zelaschi 1985: 87).

\section{Escrituras burocráticas, escrituras de afición}

La literatura y el periodismo de fines del siglo XIX alcanzan y sobran para explicar la temprana tentación narrativa entre investigadores de la policía de Buenos Aires. Pero otro origen no menos decisivo reside en los géneros burocráticos donde cada día se relataban las peripecias de la calle, el conflicto, la transgresión, la investigación, pues la policía es (siempre ha sido) la agencia estatal más sistemáticamente abocada al registro escrito de la vida urbana (Milliot 2006). De esos géneros policial-burocráticos, el más antiguo era el sumario.

Cuando se denunciaba un crimen, la principal intervención de la policía consistía —y ha consistido por casi dos siglos - en reunir la evidencia recogida en las horas inmediatamente posteriores al hecho, hasta la intervención del juez de instrucción (Rebollo 1916: 13-17). En toda comisaría moderna, entonces, ha habido policías dedicados a pasar al lenguaje escrito los relatos orales de los testigos. Esa narrativa estaba destinada a abrir y nutrir causas, no a decidirlas. En otras palabras: funcionaba como disparador de la justicia, donde luego se retomaban y procesaban los datos según regímenes de verdad y criterios de admisibilidad altamente codificados. Así pues, la policía traducía peripecias de patrullaje y escenas de comisaría a un sumario, que debía ser compatible con otra burocracia, la judicial. (En esta transmisión reside la frontera más crítica entre policía y justicia, y una de sus principales zonas de tensión.)

Para guiar esta práctica narrativa, los agentes sumariantes se han servido del saber-hacer adquirido y transmitido por los veteranos del oficio: adaptación según el juez de turno, manejo de los tiempos y dosificación de la información en relación a la justicia y los medios de comunicación de cada época (Bianciotto 2014: 305). Antes de eso, los sumariantes han recurrido a manuales especiales. Allí se indicaban las reglas procedimentales (quién podía intervenir sobre quién, y en qué circunstancias) y se proveían los formularios para cada instancia de transcripción de incidentes, delitos o accidentes. El sumario, se indicaba a los policías, "no es una monografía jurídica o científica médica ni una prueba de literatura”. Sí requiere simplicidad y claridad, "con lo cual se facilitará al juez todo lo más posible para que pueda formarse un juicio, una impresión clara de la naturaleza y circunstancias del delito.” (Rebollo 1916: 33; Coquibús 1958: 790).

La misión del sumario era relatar una historia verosímil, que reservaba lugar para detalles y peripecias. Una codificación estricta regía el encabezamiento, pero luego el texto podía avanzar con libertad considerable en la recolección y exposición de pruebas y testimonios. A diferencia de la causa judicial, que se engrosaba con tiempo y múltiples intervenciones, el sumario surgía de una sola pluma, "en caliente”, con rapidez y astucias del oficio. Era una narración recogida en la comisaría a partir de lo ocurrido en la calle "hace aproximadamente una hora", que testigos e imputados relatan sin mediación (ni prevención) de un abogado. El texto que escribía ese policía era el primer registro del incidente en cuestión, y debía responder a una estética estatal, a una forma capaz de convertir la suma de narrativas orales en una versión que lograra abrir un expediente. El inmenso "poder sumarial” de la policía reside precisamente en esa posibilidad de narrar primero que nadie, de establecer los carriles de sentido por los que transcurrirán las reconstrucciones ulteriores. Es una forma de poder que necesita del cultivo de capacidades específicas de escritura. Y del más somero vistazo a estos documentos se desprende la posibilidad de una deriva narrativa. La opción periodística o memorialística no está lejos del oficial sumariante, que además de escribir diariamente, lee folletines y quizás también libros.

El segundo género burocrático que subyace a las crónicas de los detectives porteños es el informe de pesquisa, producido en el seno de la División Investigaciones. Área clave del Departamento de Policía, esta repartición era descendiente de la Policía de Pesquisas, formalizada en 1886. Su intervención (con jurisdicción sobre todo el territorio de la ciudad) incluía áreas tan críticas como "Robos y Hurtos”, "Defraudaciones y Estafas", "Identificación” y reparticiones dedicadas al espionaje político. En Investigaciones nacieron los prontuarios policiales. Y allí también se desarrolló una burocracia especializada en la redacción de "casos”, cuyos avances parciales se elevaban al jefe de sección, quien a su vez se servía de estos insumos para la redacción de un informe 
anual a la jefatura. A veces, los veteranos de Investigaciones se sentaban a escribir, tentados por alguna editorial, por contactos periodísticos, o por el deseo de dejar testimonio a los discípulos en el métier de la detección.

Escribir es (siempre ha sido) una tarea importante del policía de investigación. La observación etnográfica contemporánea muestra que en estas reparticiones se pasa mucho tiempo traduciendo la evidencia disponible a los lenguajes institucionales. Los estudios son convergentes: el detective-empleado dedica la mitad de sus esfuerzos a "legalizar" los casos— es decir, a transformar los hallazgos a informes escritos, de tal manera que la formulación de los expedientes satisfaga requerimientos formales (Greenwood 1979; Tarling y Burrows 1985; Thornton 1991). Lamentablemente, no disponemos todavía de estudios del quehacer de los detectives argentinos (o latinoamericanos en general), aunque hay pocas dudas en relación al peso de la narrativa burocrática en la escritura sobre la investigación del crimen. Al trasladar casos para la pedagogía o el entretenimiento, los policías traían al ámbito de la cultura masiva destrezas adquiridas en años de cultivo de otros géneros, con reglas expresivas y propias reglas de verosimilitud.

\section{Ser pesquisa en un mundo de pesquisas}

En Buenos Aires, la tradición de crónicas de la pesquisa se desarrolló inicialmente bajo la moda del folletín, las causas célebres, los "misterios de la ciudad" y la literatura de enigma, que involucraba a los profesionales de la detección a la vez como consumidores y partícipes.

A fines del siglo XIX, cuando el crimen se consagraba como tema de entretenimiento masivo, y el detective devenía en personaje de la imaginación colectiva, la práctica de la investigación criminal de la policía de Buenos Aires atravesaba un umbral importante de profesionalización. Esto involucraba dos dimensiones centrales: la constitución de una rama específica (la mencionada División Investigaciones) y la adopción de un conjunto de técnicas, como la dactiloscopia y la balística. ${ }^{7}$ Así pues, los investigadores de la policía adquirían su expertise en una sociedad donde dicho quehacer constituía el objeto de discursos de estatus muy diverso - científico y profano, real, semi-real, ficcional. Como hemos visto, el giro de la literatura tuvo ecos en las publicaciones de la profesión. La Revista de Policía pronto publicó crónicas informales de la investigación, firmadas por miembros de

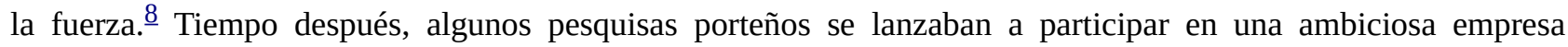
periodística.

En 1911 aparecía la revista semanal Sherlock Holmes, "como consecuencia de una necesidad que existe”. Proponía desarrollar, mediante investigaciones propias, las fragmentarias noticias policiales de los diarios:

Sherlock Holmes hará su pesquisa propia; intervendrá en todas las incidencias de la vida policial metropolitana, para reconstruir con sus datos la escena en sus más mínimos detalles; para presentarla con todos sus matices de novela; con toda su intensidad de delito $(\ldots)^{\underline{9}}$

El nombre de la revista habla del éxito que auguraba la figura del detective inglés a una empresa de ambiciones masivas. Usando definiciones de la pesquisa que abarcaban la práctica de profesionales, amateurs, imitadores y bromistas, el magazine de "lo policial" dedicaba páginas a juegos de "gentlemen detectives", y a folletines apócrifos como "Sherlock Holmes en Buenos Aires”, firmado por Juan de León. El semanario compendiaba todo lo que ofrecía la frontera periodística de "lo policial”, que era mucho (Caimari 2015). En poco tiempo, Sherlock Holmes acusaba 50.000 ejemplares semanales.

El lugar de la policía en esta empresa era a la vez omnipresente e inestable. Ciertamente, Sherlock Holmes era una revista amiga de la fuerza, pero generaba un tipo de exposición de implicancias ambiguas. Como en las ficciones de Eduardo Gutiérrez, volvieron a circular aquí los nombres de jefes de policía de la vida real. En "Sherlock Holmes en el Plata”, folletín publicado en tres entregas, se describía la visita del famoso detective y su amigo y narrador, Watson, llamados a auxiliar a la policía porteña en su lucha contra el anarquismo. El centro del relato transcurría en el Departamento de Policía, donde Holmes (inicialmente sospechoso de responsabilidad en el 
crimen) explicaba al sorprendido nuevo jefe, Luis Dellepiane, la trama oculta del caso. Tras una laberíntica historia de huellas, disfraces y confusiones de identidad, los policías se entregaban a la superioridad del detective, y lograban capturar al temible Simon Radowitzky. "El orden y la tranquilidad están asegurados por mucho tiempo en Buenos Aires”, decía Watson. “Nos volvemos a Londres”. 10

En estos juegos había un distintivo alarde de intimidad con la policía. Se hablaba del quehacer de la institución en tono familiar, cuando no se hacía propaganda lisa y llana. La cobertura de pesquisas entró en este marco, que incluía la promoción de las bondades de la División Investigaciones y la celebración de la pericia de sus detectives. Pero aun si no había dudas en relación a la vocación filo-policial, la lógica periodística (masiva y divertida) imponía otras reglas. Con el tiempo, apareció el reportero-detective ficcional "Sifro", que resolvía casos mejor que la policía. Y en este marco a la vez tentador e incierto se difundió, también, la palabra de los policías detectives. Apelando a su arma principal — la autoridad que otorgaba acceso a información exclusiva, la experiencia en la escena del crimen — varios ofrecieron a Sherlock Holmes la narración de "Una de mis pesquisas”.

¿Qué relataban los "pesquisantes”? Indagaciones relativamente sencillas ocurridas durante su actividad en la fuerza, módicos misterios del pasado, reconstruidos con lenguajes más o menos adaptados al medio periodístico (en algunos casos, los mismos textos burocráticos eran reproducidos sin modificaciones). $\frac{11}{}$ La figura central no era el detective "puro" sino el comisario, el subcomisario, o algún suboficial asignado a la comisaría, que exhibía destrezas deductivas gracias a sus potestades de investigación sumarial. Ese pesquisante combinaba los ademanes de la experiencia callejera del policía con la adhesión a la figura del detective literario.

Veamos el caso del Comisario Jubilado, que en 1912 relató una pesquisa ocurrida 25 años antes en su jurisdicción. $\underline{12}$ Como en la mayoría de estos textos, la narración se mantenía cerca de las rutinas urbanas del baqueano-policía: "En la noche del 25 de Mayo del año 1887, al regresar de una recorrida que hiciera en el radio de mi sección..." Lo que seguía combinaba la exhibición de la experiencia del comisario porteño ("Los comisarios estamos hartos,- - porque el caso es el común en Buenos Aires- de recibir denuncias sobre robos y escamoteos en la vía pública.”) con el prestigio del detective cerebral:

Durante mi larga actuación policial, he llegado a erigir en axioma elemental el principio de que, dentro de las paredes del despacho del Comisario, nada se estudia ni nada se resuelve. Lo mejor es, durante la noche, en la cama, analizar el caso con toda tranquilidad, por la vía hipotética que tanta fama ha dado al ilustre pesquisante cuyo nombre sirve de título a esta novedosa revista.

Luego de este saludo al detective mental de las ficciones tan de moda, el caso se resolvía con ingenio y tretas muy propias de las práctica policial cotidiana: el recurso al seguimiento nocturno (sin uniforme) hacia "lo que policialmente llamamos ‘la combinación’”, el arresto y la confesión. El relato remataba con saberes de comisaría:

Teniendo preso al pájaro, la solución del misterio duró muy poco. Un detenido es siempre un hombre dispuesto a "cantar” y á decir la verdad, si el interrogatorio á que se lo somete es llevado con habilidad, que sólo da la práctica. $\underline{13}$

En última instancia, los saberes nacidos de la acumulación de la experiencia eran los que zanjaban la cuestión. Y ninguno entre ellos más importante que las destrezas del interrogatorio. En este sentido, las narrativas tempranas de la pesquisa policial muestran el germen de un elemento que se consolidaría en las memorias de detectives porteños de entrado el siglo XX, que exaltaron el manejo del interrogatorio como elemento de distinción rea del buen detective policial (Meneses 1964; Urricelqui 1977).

Por el momento, estos “detectives” porteños del cambio del siglo eran tales sólo entre comillas: en su mayoría, eran comisarios con potestades judiciales o escribientes entrenados en el resumen de casos. Tal es el origen de la mayor parte de las narrativas policiales escritas por "detectives" policías en revistas propias o ajenas, y también las que aparecían en las Memorias de un detective de Dellepiane (1912), o los cuentos del comisario Laurentino 
Mejías. No obstante los ademanes correctivos y la denuncia de los errores del profano, la primera escritura informal de la pesquisa nacía entre el memorialismo de oficio y la tímida incursión en el gran torrente de la narrativa del crimen.

\section{NOTAS}

1 Revista de Policía (en adelante, $R P$ ), 16 de julio de 1930, p. 960.

$\underline{2}$ “Programa”, $R P, 1$ de junio de 1888, p. 1.

$\underline{3}$ “El criminal Castruccio”, RP, 25 de agosto de 1888, p. 72.

4 “Rastros del crimen”, $R P, 15$ de junio de 1888, p. 1.

5 Revista de Policía de la Provincia de Buenos Aires, 15 de diciembre de 1900, p. 192.

$\underline{6}$ En el mismo sentido: "Los dramas criollos, policialmente considerados", RP, 16 de julio de 1900, p. 57.

Z Aunque existía una policía "secreta” desde los inicios mismos de la institución, la Policía de Pesquisas no logró entidad formal (en presupuesto y reglamento) hasta 1886, bajo la dirección de José S. Álvarez (el futuro Fray Mocho). A partir de 1897, la repartición pasó a denominarse “Comisaría de Investigaciones” (Romero 1986).

$\underline{8}$ “Mi primera pesquisa. Éxito y fracaso”, $R P, 16$ de junio de 1903, p; “Los hurtos de una devota”, $R P, 16$ de julio de 1903, p. 39, p. 68.

$\underline{9} S H, N^{\circ} 1$, 4 de julio de 1911, p. 1.

10 SH, 22 de octubre de 1912, s/p.

11 Miguel Peyre, "Una de mis pesquisas”, SH, 16 de julio de 1912, p. 18; Auxiliar Fidel E. Zabala, "Una madre que degüella a su hija”, SH, 30 de julio de 1912, p. 31; Alberto Dellepiane (Comisario de la secc. 29), "Un crimen autorizado", SH, 23 de abril de 1912, p. 53.

12 Comisario Jubilado, “El sombrero ribeteado” (Memorias de un comisario de policía)”, SH, 19 de septiembre de 1911, pp. 68-69.

$\underline{13}$ Ibidem. Énfasis agregado.

\section{BIBLIOGRAFIA}

Barry, Viviana (2008). “Lecturas de policías. La Revista de Policía de la ciudad de Buenos Aires”, Papeles de trabajo. Revista electrónica del Instituto de Altos Estudios Sociales de la UNGSM, Año 2, nº 3, junio.

Bianciotto, María Laura (2014). "Previsión, anticipación y viveza. A propósito de la relación entre prácticas policiales y ámbito judicial en Rosario”, en S. Frederic, M. Galvani, J. Garriga Zucal y B. Renoldi (eds.), De armas llevar. Estudos antropológicos sobre los quehaceres de policías y de las fuerzas de seguridad, Buenos Aires, Ed. EPC.

Borges, Jorge Luis (1945). “La espada dormida”, Sur, nº 127, mayo.

Caimari, Lila (2012). Mientras la ciudad duerme. Pistoleros, policías y periodistas en Buenos Aires, 1920-1930, Buenos Aires, Siglo XXI. 
Caimari, Lila (2013). "Police, tango et argot: culture policière et culture populaire à Buenos Aires au XXe siècle", Histoire, économie \& société, $\mathrm{n}^{\circ}$ 4, pp. 41-48.

Caimari, Lila (2015). “Lecturas policiales porteñas”, en: Setton (comp.), Fuera de la ley, 47-63.

Coquibús, Juan Emilio (1958). Código Penal. Síntesis penal, procesal y sumarial, Buenos Aires, La Prensa Médica Argentina.

Dellepiane, Alberto (1912). Memorias de un detective, Buenos Aires, s/d.

Foucault, Michel (1996). La verdad y las formas jurídicas, Gedisa, Barcelona.

Frisby, David (2007). Paisajes urbanos de la modernidad. Exploraciones críticas, Bernal, Universidad Nacional de Quilmes.

Galeano, Diego (2009), Escritores, detectives y archivistas. La cultura policial en Buenos Aires, 1821-1910, Buenos Aires, Teseo/BN.

Galeano, Diego 2016). Criminosos viajantes. Circulações policiais entre Rio de Janeiro e Buenos Aires, 18901930, Rio de Janeiro, Ministério da Justiça-Archivo Nacional.

García Ferrari, Mercedes (2015). Marcas de identidad. Juan Vucetich y el surgimiento transnacional de la dactiloscopia: 1888-1913, Rosario, Prohistoria.

Johnson, Diane (1985). Dashiell Hammett. Biografía, Barcelona, Seix Barral.

Kalifa, Dominique (2013). Les bas fonds. Histoire d'un imaginaire, Paris, Seuil.

Lafforgue, Jorge y Rivera, Jorge (1996). Asesinos de papel. Ensayos sobre narrativa policial. Buenos Aires, Colihue.

Laplaza, Francisco (1945). “Antecedentes de nuestro periodismo forense hasta la aparición de la 'Revista Criminal'“. Revista Penal y Penitenciaria, Tomo X.

Locard, Edmond (1934). Policías de novela y policías de laboratorio, Buenos Aires, Biblioteca Policial.

Meneses, José Evaristo (1964). Meneses contra el hampa, Buenos Aires, Ed. Mam.

Miller, D. A. (1988). The Novel and the Police. Berkeley U. of California Press.

Milliot, Vincent (dir.) (2006). Les Mémoires policières, 1750-1850. Écritures et pratiques policières du Siècle des Lumières au Second Empire, Rennes, Presses Universitaires de Rennes.

Monjardet, Dominique (1994). Ce que fait la police. Une sociologie de la force publique, Paris, La Découverte.

O’Brien, Geoffrey (1997). Hardboiled America. Lurid Paperbacks and the Masters of Noir, Nueva York, Da Capo Press.

Pérez Zelaschi, Adolfo (1985). "Policía verdad - policía ficción. Algunos apuntes sobre la narrativa y el cine policial y su relación con la realidad”, Mundo Policial, abril 1985, pp. 85-86.

Raczkowski, Christopher (2003). “From Modernity’s Detection to Modernist Detectives: Narrative Vision in the Work of Allan Pinkerton and Dashiell Hammett”, Modern Fiction Studies, vol. 49, nº 4.

Rebollo, Juan Carlos (1916). Manual del sumariante de policía. Buenos Aires, Talleres Gráficos Rodríguez-Giles. Romero, Alberto J. (Comisario Inspector R.) (1986). “Breve historia de la Policía de Investigaciones”, Mundo Policial, Año 18, nº 54- Año 24 nº 76. 
Setton, Román (2009). "Raúl Waleis y los inicios de la literatura policial argentina”, en Raúl Waleis, La huella del crimen, Buenos Aires, Adriana Hidalgo.

Setton, Román (2015). “La literatura policial argentina entre 1910 y 1940”, en AAVV, Fuera de la ley. 20 cuentos policiales argentinos. Edición, introducción y notas de Román Setton, Buenos Aires, Adriana Hidalgo.

Shpaier Makov, Haia (2006). "Explaining the Rise and Success of Detective Memoirs in Britain”, en Clive Emsley y H. Shpayer-Makov, Police Detectives in History, 1750-1950, Burlington (VT, EEUU), Ashgate.

Shpaier Makov, Haia (2011). The Ascent of the Detective. Police Sleuths in Victorian and Edwardian England,Oxford, Oxford University Press.

Shpaier Makov, Haia (2012). "Shedding the uniform and acquiring a new masculine image. The case of the lateVictorian and Edwardian English police detective”, en D. Barrie y S. Broomhall (eds.), A History of Police and Masculinities, 1700-2010, Nueva York, Routledge.

Sirimarco, Mariana (2010). "Memorias policiales. Narrativas de emotividad”, en Publicar - En Antropología y Ciencias Sociales, Año VIII, nº IX, pp. 127-143.

Tarling, Roger y John Burrows (1985). “The Work of Detectives”, Policing, vol. 1, nº 1, pp. 57-62.

Thomas, Ronald (1999): Detective Fiction and the Rise of Forensic Science. Cambridge: Cambridge University Press.

Thornton, G. (1991). "Detectives or Clerks? Anexamination of the work of detectives", Department of Social Administration, Manchester University. Recuperado de: www.xrce.xerox.com/content/download/.../EPC-1991109.pdf

Urricelqui, Evaristo (1977). Careo, Buenos Aires, Yala.

Waddington, P. A. J. (1999). Policing Citizens. Authority and Rights, Nueva York, Routledge.

Yi-Fu-Tuan (2008). Space and Place. The perspective of experience, Minneapolis, U. of Minnesota.

Zappietro, Eugenio (1981). "Vigencia de la novela policial: sobre la nostalgia y la evasión”, Mundo Policial, abriloctubre, p. 86. 